\title{
Misoprostol only or in combination with intra cervical Foley's catheter for termination of the second trimester demise pregnancy in patient with previous caesarean sections
}

\begin{abstract}
Objective: Termination of second trimester pregnancy is unique obstetric contest due to its difficulty and risky especially if the condition is associated with prior Caesarean deliveries.

Aim of the work: To compare the safety and efficacy of two regimens for termination of the second trimester pregnancy in ladies with scarred uterus by prior Caesarean deliveries either by using sublingual and vaginal misoprostol or sublingual misoprostol in a combination with intra cervical Foley's catheter.

Patients and methods: 163 pregnant ladies with second trimester demise pregnancy at14-24 gestational weeks in scarred uterus ( $\geq$ one cesarean sections) participated in this prospective randomized comparative study which was performed in obstetric emergency unit in Zagazig University Hospitals, Egypt from June 2019 to May 2020. 140 patients only far-reached the trial through termination of the pregnancy via induction of abortion by sublingual and vaginal misoprostol Group 1 (GI) or Foley's catheter with vaginal misoprostol Group 2 G (II). Whichever of those methods sustained for 48 hours else the fetus expulsed formerly .Outcomes was determined by comprehensive expulsion of fetus and placenta, Induction Abortion interval, Incidence of side effects, requirement for surgical intervention and complications" rate.
\end{abstract}

Results: The demographic criteria of both groups revealed no significant difference (P-value $>0.05$ ). The mean (SD) of Induction to abortion interval (hours) in GI was significant longer than in G II $(51.07 \pm 23.84,45.20 \pm 31.28)$ respectively with (P- value $0.021)$.

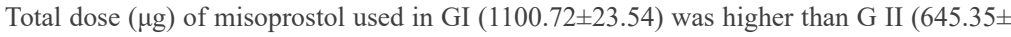
322 ) with $\mathrm{p}$ value 0.001 . Admission-termination hospitalization (days) was significant longer in G I (4.11 \pm 1.02$)$ than in G II $(2.371 \pm 1.98)$ with P value 0.004 .

No significant difference as regard occurrence of adverse effects between both groups except the incidence of fever (17.1\%) in G I and (5.7\%) in G II with P value 0.01 .

Success rate in GI and G II were $(80 \%, 95 \%)$ respectively with P-value 0.01 . Incomplete expulsion was higher in GI (14.3\%) in comparison with G II (4.2\%) with P value 0.04 . Incidence of haemorrhage was significant higher in G II than in GI P value 0.03 . No significant differences between both groups as regard incidence of rupture uterus or occurrence of infection.

Conclusion: Practice of inserting Foley's catheter through cervix with misoprostol sublingually for termination of mid-trimester pregnancy in preceding uterine scar(s) is efficient, inexpensive and safe procedure.

Keywords: mid-trimester, induction, pregnancy, abortion, termination, caesarean section, prostaglandin
Volume II Issue 6 - 2020

\section{Hend S Saleh, Mohamed El-Husseny El Kadosi, Hala E Sherif}

Department of Obstetrics and Gynecology, Faculty of Medicine, Zagazig University, Egypt

Correspondence: Hend S Saleh, Department of Obstetrics and Gynecology, Faculty of Medicine, Zagazig University, Egypt, Tel 00201 I43288238, Email hendabosaleh@hotmail.com

Received: December 24, 2020 | Published: December 30, 2020

\section{Introduction}

The universal incidence of termination of second trimester pregnancy is $10-15 \%$. Induction of abortion or labor is one of the commonest procedures used for termination of pregnancy and is one of the most provocative zones of obstetrical practice. ${ }^{1}$

Numerous methods are accessible for termination of second trimester pregnancy specially with unfavorable cervix. They were categorized as pharmacological, mechanical or surgical methods. Misoprostol and trans cervical insertion of Foley's catheter are examples of those methods. ${ }^{2}$
In vision of the probable side-effects and complications of such methods, abundant investigation has been conceded for those manners which had no agreement about which is the uppermost one. ${ }^{3}$ Induction of abortion by medical modes has developed along the last two decades as an alternative to surgery. ${ }^{4}$ As the synthetic prostaglandin has important role in regulation of uterine contractility through interaction with receptors of myometrial cell and its effects on cervical tissue causing softening and dilatation, it is chiefly supplanted other techniques. ${ }^{5}$ 
Misoprostol (Cytotec) is a famous synthetic prostaglandin (PGE1), analog originally used to inhibit peptic ulcer. Which is presented in a tablet formula which is stable at room temperature and cost-effective? It could be used orally, buccally, sublingually and vaginally for induction ofabortion.

Side effects of any route which are frequently gastrointestinal are dose dependent, Also, Fever which is seen in $5 \%-10 \%$ of women is resolved within several hours of stopping it. ${ }^{7}$ As a result of increasing the number of cesarean sections all over the world, The ladies with a history of previous cesarean sections who need termination of pregnancy has increased. ${ }^{8}$

Induction of abortion in patients with Previous Cesarean Section had an amplified risk of rupture uterus. It should be decided after comprehensive counseling and management. ${ }^{9}$ Induction with misoprostol could be safely achieved in 2 nd trimester as the documents of its absolute danger are omitted, nevertheless many randomized trials revealed no adversarial consequence. ${ }^{10}$

In spite, it is associated with high incidence of hyper stimulation of uterus and consequent rupture uterus mainly in ladies with prior CS, one study showed $85 \%$ success rate. ${ }^{11}$

Several guidelines are available on the safety of misoprostol in women with one previous CS. ${ }^{12}$ Transcervical extra-amniotic intra cervical insertion of Foley's catheter is another practice used to induce labor by both mechanical dilatation and encouraging release endogenous prostaglandins and this outcome is improved by traction on the inserted catheter. ${ }^{13}$

Krause in 1833 was the first one used that procedure for termination of pregnancy. Embrey and Mollison in 1967, stated successful rate of $94 \% .{ }^{14,15}$

Meanwhile there is no accessible documents on the effectiveness and safety of any means of termination of second trimester pregnancy, this current study aims to compare the safety and efficacy of two regimens for termination of the second trimester pregnancy in ladies with scarred uterus by prior Caesarean deliveries either by using sublingual and vaginal misoprostol or sublingual misoprostol in a combination with intra cervical Foley's catheter.

\section{Patients and methods}

This study was conducted in emergency unit of Obstetrics department, Zagazig university hospitals, Zagazig, Egypt from June 2019 to May 2020. 163 pregnant ladies were enrolled in this study for termination of second trimester demise pregnancy at 14-18 gestational weeks established by last menstrual period and trans abdominal ultrasound, with $\geq 1$ previous caesarean section. 23 patients were excluded from the work (Figure 1).

140 completed the study, all were accomplished the inclusion criteria;

a. Singleton pregnancy.

b. Scarred uterus

\section{c. 14-18 gestational weeks}

And exclude those women with; rupture of membrane, hypersensitivity to prostaglandins, heavy vaginal infection otherwise after strict management of infection after culture and sensitivity. The study protocol was approved by the Institutional Review Board (IRB) of Zagazig University.
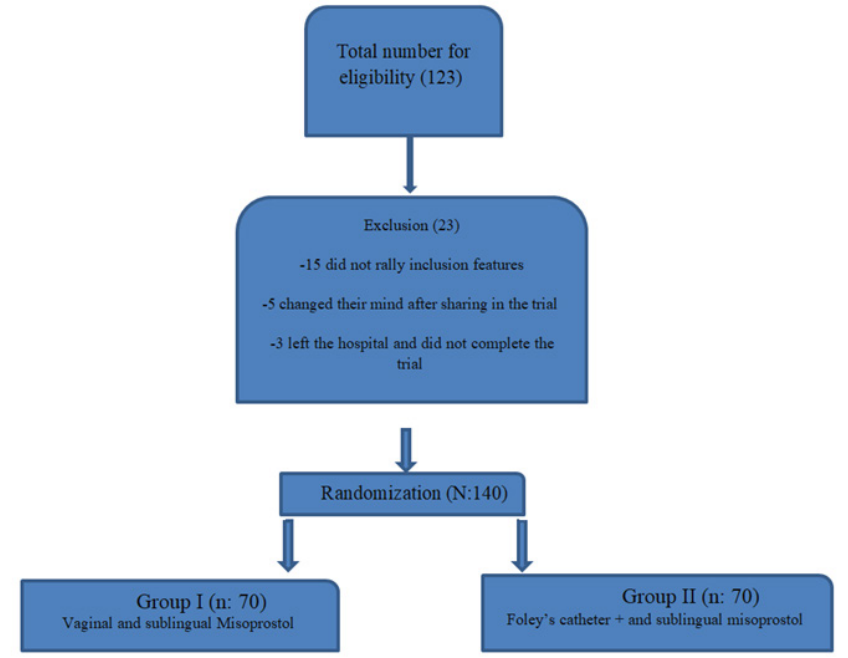

Figure I Flow chart of participants.

An informed verbal and written consent was taken from all patients after full clarification about the nature of the trial, advantages and probable complications. Physical examination and standard investigations were conceded then assigned by manual randomization to either one of the two groups, each had 70 patients.

$200 \mu \mathrm{g}$ of misoprostol tablet (Cytotec $\AA$, Ali Raif Pharm. Co, Turkey) was administered sublingually and $200 \mu \mathrm{g}$ vaginally every 6 hours. Until regular uterine contractions or up to for 48 hours. Under complete aseptic measures, in lithotomy position and empty bladder, Foley's catheter (18Fr) was introduced through cervix a far the internal Os with inflation of its balloon with $30-50 \mathrm{ml}$ normal saline. Safeguarding of the Catheter with owed traction on it then was secured by adhesive tape to the medial side of the thigh.

Collecting plastic bag filled with 200cc normal saline was connected the catheter to sure the traction. The catheter was reserved for 48hours if extemporaneous expulsion did not happen and, it was considered as failure of that method.

$200 \mu \mathrm{g}$ misoprostol sublingually was used at the same session and repetition of the dose every 6th hours till the catheter expelled or until regular uterine contractions or up to for 48 hours.

Earlier removal of the catheter if there was extreme vaginal bleeding, tenderness at the scar intolerance of the patient or spontaneous rupture of membrane and expulsion of it.

Monitoring of maternal vital signs and assessment of the cervix were done also recording the appearance of any side effects like; vomiting, nausea, diarrhea, fever, severe abdominal pain. Infusion of oxytocin at a rate of $1 \mathrm{mU} / \mathrm{min}$ was started after dilatation and effacement of the cervix $\geq 3 \mathrm{~cm}$ and could be doubled every 30 minutes till the uterine contractions turned into regular at 3-minute interval in both groups. After rupture of membrane coverage by intravenous antibiotic was started in both groups. Clinical and Ultrasonography assessment for estimating the completion of abortion. If incomplete abortion or excessive bleeding was diagnosed, surgical evacuation was achieved.

Outcomes were determined by comprehensive expulsion of fetus and placenta, induction abortion interval, incidence of side effects, requirement for surgical intervention and complications rate. 


\section{Statistical analysis}

SPSS version 22 (SPSS, Chicago, Illinois, USA) was used. The Fisher's-Exact or Chi-square test was performed for qualitative data while the Student's Mann-Whitney or U-test t-test was used for quantitative data. The $\mathrm{p}<0.05$ was considered statistically significant.

\section{Results}

140 patients were divided in two groups each one had 70 cases presented by second trimester demise pregnancy with scarred uterus ( $\geq$ one Caesarean sections) fulfilled inclusion/exclusion criteria were enrolled in this study to detect the efficacy and safety of two regimens for termination of pregnancy either by using sublingual and vaginal misoprostol (G I) or sublingual misoprostol in a combination with intra cervical Foley's catheter (G II). Demographic characters of both groups like; age (years), BMI $(\mathrm{kg} / \mathrm{m} 2)$, gravidity, parity and number of previous caesarean sections were presented in. (Table 1) There were no statistically significant differences between both Table I Demographic and clinical criteria of the studied groups groups. No significant differences between both groups as regard the mean Gestational age (weeks) at time of termination of pregnancy. There was significant difference between both groups as regard the mean dose of misoprostol necessary to prompt abortion; in G1 was $1100.72 \pm 23.54 \mu \mathrm{g}$ and $645.35 \pm 322 \mu \mathrm{g}$ in G II $(\mathrm{p}<0.001)$. Statistically there was high significant differences detected in hospitalization interval (days) $p$ value 0.004 . (Table 2) About the adversarial effects; there was significant differences as regard occurrence of fever in G1 in comparison to GII with ( $p$ value 0.01 ) but the incidence of nausea, vomiting, diarrhea and chills had no significant differences between both groups.

Success rates were $80 \%$ and $95 \%$ in G I and G II, respectively (p value 0.01). Incomplete expulsion in GI was more than in GII with statistically significant differences ( $p$ value 0.04 ). There was no statistically significant difference between these two groups in terms of rupture uterus and infection ( $p$ value 0.2 and 0 ) respectively (Table $3)$.

\begin{tabular}{|c|c|c|c|c|c|}
\hline Character & \multicolumn{2}{|c|}{ Group II(n: 70) } & \multicolumn{2}{|c|}{ Group I(n: 70) } & P-value \\
\hline Maternal age (years) & \multicolumn{2}{|c|}{$29.98 \pm 3.58$} & \multicolumn{2}{|c|}{$30.43 \pm 3.49$} & 0.125 \\
\hline BMI $\left(\mathrm{kg} / \mathrm{m}^{2}\right)$ & \multicolumn{2}{|c|}{$28.98 \pm 3.01$} & \multicolumn{2}{|c|}{$27.82 \pm 4.03$} & 0.181 \\
\hline Gravidity & \multicolumn{2}{|c|}{$3.37 \pm 1.06$} & \multicolumn{2}{|c|}{$3.11 \pm 1.18$} & 0.291 \\
\hline Parity & \multicolumn{2}{|c|}{$1.49 \pm 0.48$} & \multicolumn{2}{|c|}{$|.58 \pm 0.7|$} & 0.085 \\
\hline \multicolumn{6}{|l|}{ Number of LSCS } \\
\hline 1 & 29 & $41.40 \%$ & \multicolumn{2}{|c|}{$38.6 \% 27$} & \multirow{5}{*}{0.726} \\
\hline 2 & 22 & $31.40 \%$ & 20 & $28.60 \%$ & \\
\hline 3 & 8 & $11.40 \%$ & 10 & $14.30 \%$ & \\
\hline 4 & 10 & $14.20 \%$ & II & $15.70 \%$ & \\
\hline 5 & I & $1.40 \%$ & 2 & $2.90 \%$ & \\
\hline
\end{tabular}

Data are given as mean \pm standard deviation $( \pm \mathrm{SD}), \mathrm{P}<0.05=$ Significant, $\mathrm{BMI}$, body mass index

Table 2 Clinical features of processes of termination of pregnancy in both groups

\begin{tabular}{llll}
\hline Variable & Group I(N: 70$)$ & Group II (N: 70) & p-value \\
\hline Gestational age(weeks) at time of Termination of pregnancy (ToP) & $18.7 I \pm 4.63$ & $18.61 \pm 3.53$ & 0.299 \\
Induction to abortion interval (hours) & $51.07 \pm 23.84$ & $45.20 \pm 31.28$ & 0.021 \\
Total doses $(\mu \mathrm{g})$ & $1100.72 \pm 23.54$ & $645.35 \pm 322$ & 0.001 \\
Hospitalization (days) & $4.11 \pm 1.02$ & $2.371 \pm 1.98$ & 0.004 \\
\hline
\end{tabular}

Mean values $( \pm S D), P<0.05=$ Significant

Table 3 Adverse effects, complication and success rate

\begin{tabular}{llll}
\hline Adverse effects & Group I(N: 70) & Group II (N: 70) & p-value \\
\hline Fever & $12(17.1 \%)$ & $4(5.7 \%)$ & 0.0 I \\
Nausea or vomiting & $7(10 \%)$ & $5(7.1 \%)$ & 0.2 \\
Diarrhea & $4(5.7 \%)$ & $3(4.2 \%)$ & 0.4 \\
Chills & $9(12 \%)$ & $6(8.5 \%)$ & 0.3 \\
Complications & & & \\
Incomplete expulsion & $10(14.3 \%)$ & $3(4.2 \%)$ & 0.04 \\
Haemorrhage & $3(4.2 \%)$ & $9(12.8 \%)$ & 0.03 \\
Rupture uterus & $I(1.4 \%)$ & 0 & 0.2 \\
Infection & 0 & 0 & 0 \\
Success rate & $80 \%$ & & 0.01 \\
Success rate & & $95 \%$ & \\
\hline
\end{tabular}

$\mathrm{N}$, number; \%, percentage 


\section{Discussion}

Mid trimester demise pregnancy in ladies with prior cesarean sections is a major challenge for obstetricians, induction of abortion or labor in them needs high caution. Termination of second-trimester pregnancy can be consummate by many procedures to solve the associated problem of unfavorable cervix.

Several regimens are accessible nowadays. Medical regimens continue to progress and are revised to offer finest and harmless preferences for the females looking for pregnancy termination. The achievement of this method depends on many issues like the schedule used, dosage and plan.

The current study investigated two different means for induction of abortion for termination of second trimester demise pregnancy. Misoprostol (Vaginal and sublingual) used in Group I as a pharmacological method, trans cervical Foley's catheter insertion with traction to enhance its effect. \{a mechanical method\} combined with misoprostol sublingual used in GII.

In current study no significant differences between the patients of both groups as regard to demographic criteria like mean age (years), BMI, Gravidity, parity or number of previous cesarean sections. No statistically significant differences between both groups in respect to the mean gestational age (weeks) which was $18.71 \pm 4.63$ in G I and $18.61 \pm 3.53$ in G II.

These results were agreed with those of Mohamed et al. ${ }^{16}$ study 2017. There was a significant difference among the two groups as regard induction to abortion interval (hours) which was longer in GI $(51.07 \pm 23.84)$ than in GII $(45.20 \pm 31.28)$ with P value 0.02 , that agreed with study of Rafik et al. ${ }^{17}$ whose study was on the same type of patients but, their groups of patients were three instead of two in ours.

Rate of success in their study was (100\% in group of combination of misoprostol with intra cervical catheter and $91.4 \%$ in the group of misoprostol only with significant difference $\mathrm{p} 0.02$ ). This is Covenant with ours as the Success rate was $95 \%$ and $80 \%$ in the group of combination and the group of only misoprostol respectively with $p$ value 0.01 which had significally difference.

In study of Saim et al. ${ }^{18}$ they found the success rate of misoprostol was $84.89 \%$ in inducing abortion in 2nd trimester with prior one cesarean section which was agreeing with our result as regard misoprostol. Emine Aydin, Ozgur Ozyuncu 2019. ${ }^{19}$ studied use of two regimens of misoprostol in inducing abortion in patient of second trimester pregnancy with previous Caesarean section $50 \mu \mathrm{g}$ versus $200 \mu \mathrm{g}$ inserted vaginally every six hours established significant difference as regard Successful rates which was $91.8 \%$ and $99.1 \%$ in first group and second one respectively $(\mathrm{p}<0.001)$.

As regard to unaccompanied use of misoprostol, FIGO has suggested protocol regime for second trimester pregnancy termination by $100-200$ meg vaginally, every 6 hours up to 4 doses/24 hours. ${ }^{20}$

As regard total dose $(\mu \mathrm{g})$ of misoprostol used in this study, there was significant difference between both groups which is less in GII $(645.35 \pm 322)$ than GI $(1100.72 \pm 23.54)$ with P-value 0.001. Also about interval from admission to start induction to abortion and discharge \{total hospitalization (days)\} was significant longer in GI $(4.11 \pm 1.02)$ than in GII $(2.371 \pm 1.98)$ with P-value 0.004 . That agreed with study of Rafik et al. ${ }^{17}$

No significant differences as regard Side effects like, nausea or vomiting, diarrhea or chills but fever had higher incidence in GI than GII with P value 0.01 , these may agree or disagree with many studies which may be related to more high or less total doses of misoprostol used.

Complications similar to incomplete expulsion was more in G I than GII with P- value 0.04 but haemorrhage was more in G II than GI with P-value 0.03 . No recorded cases of infection and no significant differences between both group as regard the occurrence of rupture uterus. That was not agreeing with study of Rafik et al. ${ }^{17}$ who found no statistically significant differences between those groups as regard haemorrhage.

Many studies found no significant difference in induction of midtrimester abortion by misoprostol between patients with previous C.S and who had not in the incidence of occurrence of haemorrhage or uterine rupture. Fawzy $\mathrm{M}$ et al. ${ }^{21}$ and West $\mathrm{H}$ et al. ${ }^{22}$

\section{Conclusion}

The combination of misoprostol with a Foley catheter through cervix is a reliable rapid and uncomplicated procedure for termination of mid-trimester pregnancy with preceding uterine scar(s).

\section{Acknowledgments}

None.

\section{Ethical approval}

The study was approved by the Institutional Ethics Committee.

\section{Funding}

No funding sources.

\section{Conflicts of interest}

The authors declare that there are no conflicts of interest.

\section{References}

1. Lalitkumar S, Bygdeman M, Gemzell-Danielsson K. Mid-trimester induced abortion: a review. Human Reprod Update. 2007;13:37-52.

2. Jozwiak M, Dodd J. Methods of term labour induction for women with a previous caesarean section. Cochrane Database Syst Rev. 2013;3:CD009792.

3. Sananès N, Rodriguez M, Stora C, et al. Efficacy and safety of labour induction in patients with a single previous Caesarean section: a proposal for a clinical protocol. Arch Gynecol Obstet. 2014;290:669-676.

4. Borgatta L, Mullally B, Vragovic O. Misoprostol as primary agent for medical abortion in low-income urban setting. Contraception. 2004;70:121-123.

5. Bhattacharjee N, Ganguly RP, Saha SP. Misoprostol for termination of mid-trimester post-caesarean pregnancy. Aust NZ J Obstet Gynecol. 2007; 47:23-25.

6. Elati A, Weeks AD. The use of misoprostol in obstetrics and gynaecology. Br J Obstet Gynecol. 2009;116:61e9.

7. Khan RU, El-Refaey H. Pharmacokinetics and adverse-effect profile of rectally administered misoprostol in the third stage of labor. Obstet Gynecol. 2003;101:968e74.

8. Hamilton BE, Martin JA, Ventura SJ. Births: preliminary data for 2011 National vital statistics reports: from the centers for disease control and prevention, National center for health statistics, National vital statistics system. 2012;61(5):1-18. 
9. Ravasia D, Wood S, Pollard J. Uterine rupture during induced trial of labor among women with previous cesarean delivery. Am J Obstet Gynecol. 2000;183:1176-1179.

10. Herabutya Y, Chan Rachakul B, Punyavachira P. Induction of labour with vaginal misoprostol for second trimester termination of pregnancy in the scarred uterus. Int J Gynecol Obstet. 2003;83:293-297.

11. Daskalakis FJ, Mesogitis SA, Papantonious NE. Misoprostol for 2nd trimester pregnancy termination in women with prior cesarean cases. BJOG. 2005;42:97-99.

12. Borgatta L, Kapp N, Society of Family P. Clinical guidelines. Labor induction of abortion in the second trimester. Contraception. 2011;84(1):4-18.

13. Jozwiak M, Rengerink K, Benthem M, et al. Foley catheter versus vaginal prostaglandin E2 gel for induction of labour at term (PROBAAT trial): an open-label, randomised controlled trial. Lancet. 2011;378(9809):2095-2103.

14. Hamilton J. Historical review of British obstetrics and gyneacology. Edinburgh, Livingston; 1954:1800-950.

15. Embrey MP, Mollison BG. The unfavor rable cervix and induction of labor using a cervical balloon. Journal of obstetrics and gynaecology of the British Commonw wealth. 1979;74:44-48.
16. Fathalla M, Amr M Maghraby, Tarek K AL-Hussaini, et al. Different methods of termination of second trimester pregnancy at Women's Health Hospital, Assiut University: efficacy and complications. Int J Reprod Contracept Obstet Gynecol. 2017;6(8):3241-3246.

17. Rafik I, Hanan N, Mohamed N, et al. Different methods of termination of second trimester pregnancy with scarred uterus at Mansoura University Hospitals, Egypt. J Fertill Steril. 2020;24(2):27-34.

18. Saim a Ashraf, Amara Sahar, Sohail Safdar. Inducing abortion 2nd trimester; efficacy of misoprostol with one cesarean section. Professional Med J. 2017;24(6):839-842.

19. Emine Aydin, Ozgur Ozyuncu. Low-dose misoprostol for second trimester pregnancy termination in women with a prior caesarean delivery. Journal of Clinical and Diagnostic Research. 2019;13(11):QC05-QC07.

20. FIGO Guidelines. Treatment of postpartum hemorrhage with misoprostol. Int J Gynecol Obstet. 2012;119:215-256.

21. Fawzy M, Abdel-Hady el-S. Midtrimester abortion using vaginal misoprostol for women with three or more prior cesarean deliveries. International Journal of Gynaecology and Obstetrics. 2010;110(1):50 52.

22. West HM, Jozwiak M, Dodd JM. Methods of term labour induction for women with a previous caesarean section. Cochrane Database of Systematic Reviews. 2017. 